\title{
Analisis Dampak Penerapan Milk District Model Nestle Terhadap Aksesibilitas Livelihood Assets Peternak Sapi Perah di Jawa Timur (Studi pada Empat Wilayah Penampungan Susu Segar)
}

\section{Analysis the Impacts of Application of Milk Dictrict Model Nestle for Livelihood Assets Accessibilities of Dairy Farmers in the Province of East Java}

\section{B.A. Nugroho dan P.S. Winarto}

\author{
Fakultas Peternakan Universitas Brawijaya, Malang \\ Jl. Veteran Malang, 65145. Jawa Timur \\ e-mail: bamalnug@yahoo.com
}

(Diterima: 23 April 2011; Disetujui: 3 Juni 2011)

\begin{abstract}
East Java province is one of the development centre of dairy farming in Indonesia. In 2008, dairy farming activities in East Java constitue is about 88,148 dairy farmers, 29 dairy cooperatives, 130,000 dairy cows, and produces 600,000 litres freshmilk per day, from that amount 410,000 litres marketed to PT. Nestle. This study was conducted to analysis macro impact of milk district model Nestle on 1) labor absorption, natural resources conservation, and regional economic growth and 2) on capital assets accessibility of dairy farmers. Analysis methods that we used in this study were 1) field survey using questionnaire; 2) collecting secondary data; 3) in depth interview using checklist; and 4) measuring accesssibility on livelihood assets (human, natural, physics, social and financial accesss). Areas of study located on three regencies in East Java Province: Malang, Blitar and Kediri, 97 smallscale dairy farmers were surveyed. The impacts of milk district model on livelihood assets accessibilities remain significants especially on financial and social capitals. This means that dairy farmers accesssibilities on financial sources were improved because it provide regular source of income, something the dairy farmers would not receive from their seasonal crops. Accessibility level of social capital were improved too, this means that smallscale dairy farming activities capables to create many collective activities on the rural communities based on dairy farming issues through variety efforts on Artificial Insemination (AI), feeding process, freshmilk handling, freshmilk collecting, forages management, breeding, animal healthcares, etc. Accessibility level on human, physical and natural capitals remainds lower than social and financial capitals because there are a lack of human capital (knowledge, skills, creativity and adaptive strategy); a lack of physical capital (rural infrastructures); and natural capital (clean water availability).
\end{abstract}

Keywords: livelihood assets, milk district model, smallscale dairy farming

\section{PENDAHULUAN}

Produksi susu di wilayah Jawa Timur saat ini mencapai sekitar 600 ton per hari. Sebanyak 410 ton dipasarkan ke PT. Nestle, 40 ton ke PT. Imdi di Pandaan, 21 ton ke Industri Pengolah Susu di Jakarta, 10 ton ke GKSI Jawa Tengah, 30 ton ke PT. Greenfield Malang, dan sekitar 9 ton per hari diproses sendiri oleh koperasi melalui Pusat Koperasi Industri Susu (PKIS) Sekar Tanjung Pasuruan yang merupakan gabungan enam koperasi primer di Jawa Timur. Jumlah itu dihasilkan oleh sekitar 130 ribu ekor sapi.

Kondisi pada tahun 2007, PT. Nestle masih kekurangan pasokan sekitar 140 ton setiap harinya. PT. Imdi kekurangan pasokan sekitar 10 ton, PT. Greenfield kekurangan pasokan sekitar 20 ton, dan PKIS Sekar Tanjung kekurangan pasokan sekitar 30 ton. Dihitung secara keseluruhan, permintaan susu mencapai 725 ton per hari. Adapun harga rata-rata susu per liter sekitar Rp 2.200,- sampai dengan Rp 3.300,- (Dispet Jatim, 2005).

Dalam pengertian sederhana, komponen milk district model Nestle meliputi: 1) melakukan kesepakatan dengan peternak untuk melakukan pengumpulan susu segar dua kali setiap hari, 2) 
membangun chilling centers dan collection points di desa, 3) melakukan pengaturan transport susu segar dari collection centers ke IPS, dan 4) mengimplementasikan program perbaikan kualitas susu segar (Goldberg, 2005).

Penentuan lokasi pengembangan usaha sapi perah dilakukan secara mendalam melalui pengamatan berbagai faktor, meliputi: 1) kondisi eksisting produksi susu segar dan produksi potensial dari calon lokasi, mendasarkan pada sumber daya pakan, lahan, dan interest peternak terhadap usaha sapi perah. Pertanyaan kuncinya adalah dapatkah potensi lokasi akan mampu memasok bahan baku berupa susu segar bagi IPS secara berkelanjutan?; 2) kondisi eksisting biaya produksi dan harga susu segar; 3) kondisi eksisting pendapatan peternak baik dari kegiatan on-farm, off-farm maupun non-farm. Pertanyaan kuncinya adalah apakah susu segar mampu memberikan penghasilan yang memadai bagi peternak?; 4) kondisi eksisting dari milk collection systems (jika ada), keberadaaan kompetitor, kondisi kualitas susu segar serta potensi untuk memenuhi persyaratan kualitas yang akan ditetapkan.

Implementasi dari milk district model Nestle meliputi adanya jaminan food safety dan quality serta quantity, dan adanya jaminan competitiveness. Bahkan sistem food chain dimulai sebelum fase on-farm, berupa riset dan pengembangan sistem budidaya sapi perah. Hal itu dilakukan karena di negara berkembang pada umumnya akan sangat beresiko untuk melakukan pengadaan bahan baku susu segar melalui pihak ketiga tanpa membangun sistem kontrol kualitas di lokasi sentra produksi. Menurut Ackerman, et al. (2005), milk district model Nestle telah terbukti berhasil diimplementasikan di berbagai negara, antara lain di India, Pakistan, China, Brazilia, Chilie, dan sebagainya. Berbagai faktor yang menyebabkan keberhasilan tersebut meliputi adanya extension staff di tingkat desa (Agriservice Nestle), adanya peralatan penanganan dan uji kualitas susu segar di tingkat desa, adanya operator yang terlatih khususnya pada kegiatan pengumpulan susu segar. Di samping itu, juga adanya jaminan penyerapan susu segar yang diproduksi peternak oleh Nestle secara kontiniu sepanjang tahun asal memenuhi kualitas yang dipersyaratkan.

Milk district model Nestle pada tahapan implementasinya terbukti telah mampu memberikan penghasilan yang reguler bagi para peternak melalui pembayaran susu segar (di Jawa Timur dilakukan setiap sepuluh hari), hal ini akan mampu menggerakkan perekonomian keluarga peternak yang sebelumnya hanya menerima hasil panen budidaya tanaman paling cepat tiga bulan sekali. Dengan kata lain, milk district model Nestle mampu meningkatkan sirkulasi uang di wilayah sentra usaha sapi perah.

Tujuan penelitian ini untuk melakukan kajian dampak mikro penerapan milk district model Nestle terhadap tingkat aksesibilitas peternak sapi perah terhadap capital assets (human, physic, natural, social dan financial) di wilayah sentra usaha sapi perah di Jawa Timur.

\section{METODE ANALISIS}

\section{Lokasi Kajian}

Lokasi kajian dampak penerapan milk district model ditentukan secara purposive dengan argumen bahwa: 1) lokasi kajian merupakan wilayah pengembangan usaha sapi perah di Jawa Timur, 2) jumlah peternak, 3) kondisi agroklimat, dan 4) kontinuitas penyaluran susu segar ke PT. FSI/Nestle. Oleh karena unit analisis kajian ini adalah peternak, maka dilakukan sorting data jumlah peternak, selanjutnya dilakukan pengelompokan (grouping) yang hasilnya berupa tiga kelompok peternak yang menyetor susu kepada empat PPS. Berdasarkan pada kriteria sampling tersebut maka ditentukan tiga lokasi kajian, meliputi Sumber Makmur-Ngantang (Malang), Semen-Gandusari (Blitar), dan Tulus BaktiPagu (Kediri). 


\section{Metode Analisis Informasi dan Data} Jenis dan metode pengumpulan informasi dan data. Data yang dibutuhkan dalam kajian ini adalah berupa data primer dan sekunder. Data sekunder dikumpulkan secara langsung dari kelompok peternak, koperasi, agriservice Nestle dan dinas peternakan. Sedangkan data primer di kumpulkan secara langsung dari peternak responden terpilih, hal ini dilakukan melalui survey dengan menggunakan kuesioner yang meliputi profil peternak; penguasaan asset khususnya ternak dan lahan; kegiatan onfarm, off-farm dan non-farm. Dalam kajian ini juga dilakukan in-depth interview terhadap key persons dengan menggunakan checklist.

Metode analisis informasi dan data. Informasi dan data yang telah dikumpulkan dianalisis secara deskriptif kualitatif dan kuantitatif. Selanjutnya dilakukan menganalis dampak mikro milk district model Nestle, yakni kegiatan analisis data diarahkan pada aspek aksesibilitas peternak responden terhadap human (SDM), kapital, finansial, fisik dan sosial (Cleary, et al., 2003). Salah satu alat analisis yang digunakan untuk mengkuantifikasi dampak suatu program adalah pendekatan model pentagonal (capital assets). Untuk itu, dilakukan analisis lima jenis aset yang berbeda yang mana masingmasing petani "membangun" penghidupannya.

\section{HASIL DAN PEMBAHASAN Karakteristik Responden}

Umur dan pengalaman responden. Dari sejumlah 97 reponden yang dijadikan obyek kajian pada empat lokasi yaitu di Pos Penampungan Susu (PPS) Salam sejumlah 25 peternak, PPS Pagersari sejumlah 25 peternak, kedua PPS ini berada di desa Pagersari, Kecamatan Ngantang Kabupaten Malang, selanjutnya di PPS Tirtomoyo, Kecamatan Semen Kabupaten Blitar sejumlah 25 peternak, kemudian yang terakhir di PPS Pagu, Kabupaten Kediri sejumlah 21 peternak.

Berdasarkan hasil survey lapang menunjukkan bahwa secara keseluruhan umur responden adalah 43 tahun serta memiliki pengalaman beternak sapi perah sekitar 12,77 tahun. Dari segi umur, responden yang menyetor susu di PPS Pagersari umumnya masih muda, yaitu sekitar 32,44 tahun, sedangkan responden yang menyetor susu di PPS Salam, PPS Tirtomoyo dan PPS Pagu umumnya sudah berusia diatas 40 tahun. Sedangkan apabila diamati dari segi pengalaman, maka meskipun memiliki rataan usia muda, akan tetapi para responden yang menyetor susu di PPS Pagersari ternyata memiliki pengalaman beternak sapi perah yang paling lama, yaitu sekitar 15 tahun. Hal ini mengindikasikan bahwa para peternak responden yang saat ini menggeluti usaha budidaya ternak sapi perah merupakan keturunan generasi kedua atau penerus usaha orang tua mereka. Secara singkat dapat disimpulkan bahwa usaha sapi perah memiliki daya tarik yang cukup tinggi untuk dikelola sehingga para generasi muda di wilayah sentra usaha sapi perah memiliki interest yang tinggi untuk menggelutinya. Apalagi, kondisi itu ditunjang dengan adanya kenaikan harga susu segar akhir-akhir ini.

Oleh karena variasi umur para peternak yang menyetor susu pada setiap PPS berbeda maka sudah selayaknya apabila perlakuan ataupun pelayanan terhadap mereka juga berbeda, dalam artian bahwa bagi PPS dengan anggota penyetor sebagian besar berusia muda maka perlu diberikan berbagai kegiatan transfer teknologi tepat guna yang lebih intensif berkaitan dengan milk handling agar kualitas susu segar dapat terus terjaga secara berkelanjutan. Kegiatan jenis ini dilakukan agar dapat diciptakan suatu kondisi partisipasi yang tinggi dan timbulnya self responsibility dari para peternak penyetor terhadap kondisi kualitas susu segar, atau dengan kata lain para peternak penyetor secara bertahap dilibatkan dalam productline pada proses industri.

Rataan penguasaan lahan responden (hektar). Pada umumnya para peternak 
responden memiliki jenis usaha lain, selain usaha sapi perah. Hal ini dapat dilihat dari angka rataan penguasaan lahan, secara keseluruhan peternak menguasai rata-rata 0,92 hektar, yang terdiri dari sawah 0,27 hektar; tegalan 0,32 hektar; pekarangan 0,07 hektar; dan kebun 0,27 hektar. Rataan tertinggi sampai terendah, berturut-turut di PPS Pagersari 1,09 hektar; PPS Salam 0,93 hektar; PPS Tirtomoyo 0,87 hektar dan PPS Pagu 0,54 hektar. Angka rataan luasan lahan ini tidak sepenuhnya menggambarkan tingkat produktivitas lahan dalam menghasilkan pendapatan, meskipun di Pagu rataan penguasaan lahannya relatif kecil, tetapi memiliki produktivas lahan yang lebih baik dibanding lokasi lain. Hal itu disebabkan karena lahan di Pagu sebagian merupakan lahan sawah di dataran rendah yang telah memiliki jaringan irigasi yang lebih baik sehingga mampu memberikan hasil pendapatan yang lebih baik pula.

Rataan kepemilikan ternak (ST). Angka rataan kepemilikan sapi induk laktasi, secara keseluruhan sekitar 2,71 ST yang merupakan sekitar 25,70\% dari keseluruhan sapi perah yang dikelola. Sedangkan, angka rataan kepemilikan sapi induk di PPS Salam, PPS Pagersari, PPS Tirtomoyo dan PPS Pagu berturut-turut adalah 2,04 ST, 2,79 ST, 2,60 ST dan 3,52 ST.

Responden peternak yang menyetor susu di PPS Pagu, sebagian memelihara sapi jantan dewasa, hal ini dilakukan antara lain karena tingkat keberhasilan IB relatif rendah dengan angka S/C sekitar 4-6, sehingga dilakukan sekaligus IB dan kawin alam agar terjadinya kebuntingan dapat lebih terjamin. Sedangkan para peternak responden yang menyetor susu di PPS Salam, PPS Pagersari dan PPS Tirtomoyo pada umumnya relatif lebih pasrah dalam menghadapi relatif tingginya angka $\mathrm{S} / \mathrm{C}$, bahkan menurut mereka jika IB tidak berhasil maka hal itu diartikan bahwa peternak pemilik sapi induk yang di IB belum saatnya memperoleh rejeki, memang agak aneh, tapi itulah fakta lapangan, keberhasilan IB dikaitkan dengan faktor keberuntungan peternak. Mengacu dari fenomena tersebut, maka apabila diharapkan target produksi susu segar yang tinggi maka pihak koperasi dan IPS perlu memberikan solusi agar kegiatan IB dapat lebih dijamin tingkat keberhasilannya sehingga angka S/C dapat ditekan serendah mungkin atau 1. Rendahnya tingkat keberhasilan IB kemungkinan disebabkan karena faktor kualitas straw atau straw handling, maka perlu dilakukan monitoring kualitas straw dan straw handling secara reguler dan terstruktur. Konsekuensinya adalah pihak koperasi ataupun inseminator diperkenankan untuk melakukan reject apabila ditemui straw yang tidak layak, seperti $\mathrm{N}_{2}$ cair yang sudah habis atau diganti dengan es batu. Untuk melakukan hal ini mutlak diperlukan good will dan peran aktif seluruh stakeholders, yang meliputi GKSI, Koperasi, IPS, Pemerintah, serta kalangan Perguruan Tinggi.

\section{Kondisi Livelihood Assets Peternak}

Secara konseptual, livelihoods assets pentagon merupakan segi lima yang mengekspresikan keadaan relatif livelihoods assets, baik berupa fisik barang maupun nonfisik yang akumulasi keduanya diekspresikan pada suatu sumbu-poros segi lima (Gambar 1). Terdapat lima sumbu-poros, masingmasing menggambarkan livelihoods assets atau disebut pula sebagai kapital, yang pada hakekatnya merupakan indikator aksesibilitas rumah tangga peternak sapi perah pada lima macam sumber daya yang saling mempengaruhi dalam hidup dan penghidupan keseharian rumah tangga peternak bersangkutan, yaitu 1) human capital (akses kepada sumberdaya manusia), 2) social capital (akses kepada sumberdaya sosial), 3) natural capital (akses kepada sumber daya alam), 4) physical capital (akses kepada sumberdaya fisik), dan 5) financial capital (akses kepada sumber daya pembiayaan) (Ashley and Hussein, 2000).

Besarnya derajat aksesibilitas rumah tangga peternak kepada sumber daya bersifat dinamis, dipengaruhi oleh faktor internal rumah tangga maupun oleh faktor diluar kendali mereka. 


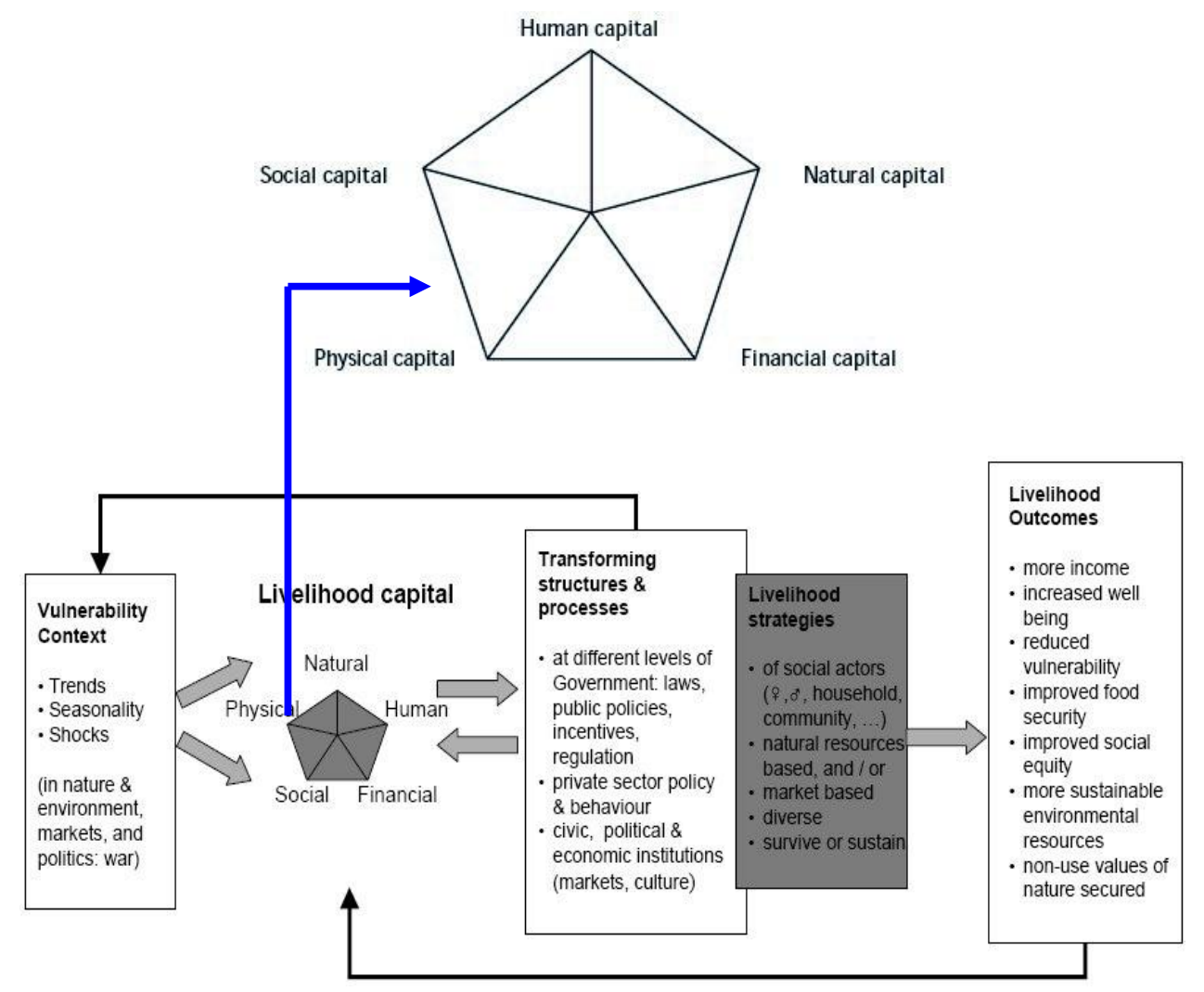

Gambar 1. Bentuk dasar livelihoods assets pentagon (DFID, 2001)

Tidak jarang livelihoods capital (assets) rumah tangga peternak menjadi rentan (vulnerable) sebagai akibat dari pengaruh trends (kecenderungan ekster nal), misalnya perubahan rezim perda gangan internasional, perubahan rezim situasi ekonomi politik domestik, dan tuntutan aplikasi inovasi produksi tertentu.

Livelihoods capital rumah tangga juga menjadi rentan tatkala terjadi wabah penyakit yang menyerang ternak maupun masyarakat luas, adanya bencana alam, serangan hama, serta konflik yang menyebabkan situasi chaos. Disamping itu, faktor seasonality antara lain berupa kenaikan harga bahan bakar minyak, harga sembako dan bahan pakan ternak, harga susu segar, menyempitnya kesempatan berusaha juga merupakan variabel yang berpengaruh pada vulnerability-context. Indikator empirik penyusun Human Capital rumah tangga peternak sapi perah, misalnya, tersusun oleh beberapa macam atribut yang direkam memakai instrumen pengumpul data serta catatan observasi lapang (field-notes) berkait dengan tingkat pendidikan formal yang diselesaikan oleh responden dan anggota rumah tangga, pelatihan atau kursus yang pernah diikuti, dinamika pola usaha ternak sapi perah, serta kemampuan rumah tangga peternak bersangkutan dalam meng antisipasi resiko usaha ternaknya. Demikian seterusnya, keempat status livelihoods assets rumah tangga peternak sapi perah sebagai petunjuk relatif derajat aksesibilitas kepada sumber daya yang melingkupi rumah tangga dan komunitasnya dikonstruksikan secara kuantitatif, dan selanjutnya diekspresikan kedalam kontinum skor yang bergerak pada skala 0 (nol) sampai dengan 5 (Tabel 1).

Bergeraknya status livelihoods assets makin jauh dari titik pusat pentagon (skor 0) bermakna semakin tinggi (baik) derajad aksesibilitas rumah tangga bersangkutan kepada sumber daya tertentu; demikian pula sebaliknya. Kategorisasi yang dibuat pada kajian ini adalah bahwa livelihoods assets skor pada rentang skor 0-2 adalah kategori rendah, skor $>2<3$ berarti kategori sedang, dan pada rentang skor 4-5 adalah baik. 


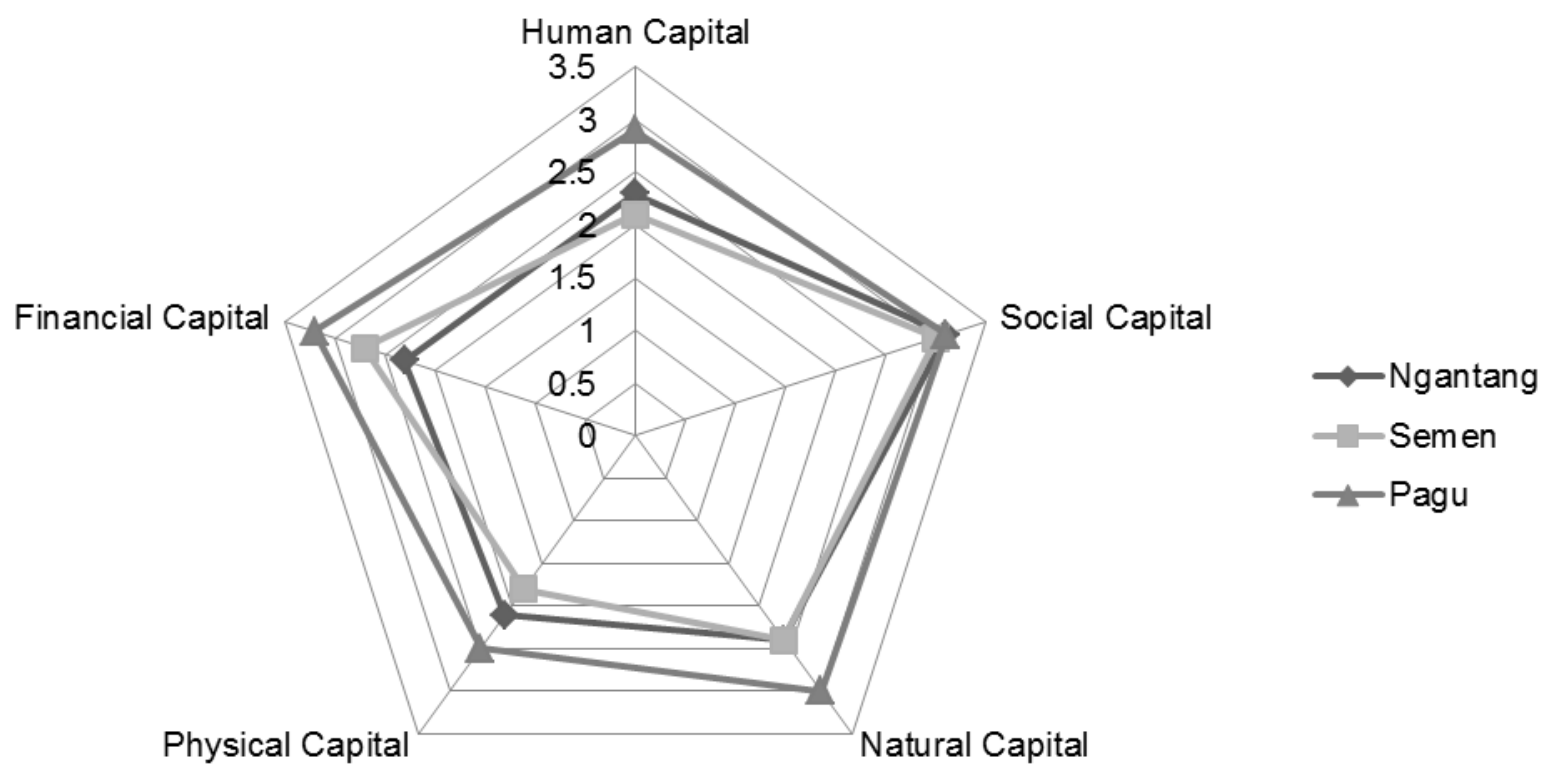

Gambar 2. Overlying livelihood assets

\begin{abstract}
Aksesibilitas peternak sapi perah kepada Human Capital. Kondisi umum di Ngantang, Semen dan Pagu menunjukkan bahwa aksesibilitas rumah tangga peternak kepada sumber daya manusia adalah sedang. Hal itu ditunjukkan dengan rataan skor sebesar 2,4. Artinya, ditinjau dari keadaan rata-rata individu yang ada di dalam rumah tangga peternak sapi perah adalah bukan warga masyarakat yang buta huruf (kepala rumah tangga maupun isteri bisa baca-tulis), dan perhatian keluarga terhadap pendidikan formal bagi anak-anak cukup memadai. Hal itu disatu sisi dimungkinkan dengan adanya kontribusi penerimaan dari bayaran susu yang secara reguler diterima oleh rumah tangga peternak, dan disisi lain karena adanya tuntutan pemenuhan kebutuhan sekolah yang berjalan secara reguler (Tabel 2 dan Gambar 2).

Rata-rata jenjang pendidikan formal yang diselesaikan oleh anggota rumah tangga peternak adalah sekolah dasar (81\%), sedangkan sebagian kecil lainnya adalah jenjang sekolah menengah pertama (7\%), sekolah menengah atas $(4 \%)$, dan perguruan tinggi (3\%). Ditinjau dari jenis pekerjaan utama responden, bagian terbesar responden mengaku bahwa beternak sapi perah merupakan pekerjaan utama mereka (59\%),
\end{abstract}

sedangkan 38\% mengaku petani sebagai pekerjaan utama mereka. Secara spesifik, responden di wilayah Pagu menunjukkan bahwa 89\% diantara peternak mengaku bahwa beternak sapi perah merupakan pekerjaan utama mereka (Tabel 3).

Indikator empirik berkenaan dengan kreativitas peternak menunjukkan bahwa mayoritas (80\%) termasuk pada kategori sedang, meskipun ada pula 10\% peternak sapi perah menunjukkan kreativitas tinggi, dan sisanya termasuk dalam kategori rendah. Kreativitas sedang nampak pada aktivitas rutin mengelola usaha ternak sapi perah yang dilaksanakan.

Dalam hal memulai beternak sapi perah, sangat jarang peternak memulai dengan membeli ternak dari uang hasil tabungannya sendiri. Namun, cara memperoleh ternak pertama kali mereka tempuh dengan menjadi tukang ngarit, mencarikan rumput untuk sapi perah milik orang lain tanpa bayaran uang (in-natura) yang berarti, tetapi bayaran diminta dalam bentuk pedet (anak sapi perah, jantan ataupun betina, maro anak).

Jika yang diberikan oleh pemilik adalah sapi perah jantan, maka si calon peternak muda (biasanya yang sudah tidak sekolah) tetap menitipkan sapi jantannya ke 
pemilik awal sambil terus bekerja ngarit untuk sapi milik majikan dan sapi jantan muda miliknya. Setelah sapi jantan muda dipandang pantas dijual, maka sapi tersebut dijual dan uang yang diterima dibelikan sapi perah dara. Tempat pembeliannya pun tidak perlu ke tempat yang jauh; melainkan antar tetangga, dan bahkan tidak jarang uang hasil penjualan sapi jantan muda diberikan kepada majikannya sendiri untuk ditukar dengan sapi perah dara. Cara seperti itu sebagian besar terjadi di wilayah kerja koperasi susu di Ngantang dan Semen, terjadi secara terus menerus, dan menjadi modus perubahan dalam livelihoods assets sebagian anak-anak muda di wilayah Ngantang dan Semen, sampai akhirnya si tukang ngarit mampu memiliki sapi perah sendiri.

Pakan konsentrat diperoleh dari pembelian yang dibayar kemudian dengan cara potongan langsung uang hasil pembayaran setoran susu. Sangat jarang peternak yang berupaya menambah pakan konsentrat; peternak tidak tahu cara menyusun ransum, hijauan pakan sapi perah diperoleh dari vegetasi alami maupun budi daya di lahan, dan proses pemerahanpenanganan susu segar cukup baik. Kandang sapinya memperoleh cukup cahaya, lantai kandang sapi telah terbuat dari batu-semen, saluran pembuangan kotoran ternak berupa galian tanah, konstruksi kandang berupa campuran kayu dan tembok beratap genting). Proses replacement ternak dan upaya memperbesar skala usaha tidak terlalu diupayakan. Telah ada upaya pemanfaatan kotoran sapi menjadi pupuk kandang, meskipun sebagian besar masih dibuang atau dibiarkan mengalir ke parit kampung. Keperluan kesehatan ternak telah memakai jasa mantri/dokter hewan/petugas yang ditunjuk oleh KUD. Ditinjau dari aksesibilitas terhadap informasi, dapat dinyatakan bahwa aktif tidaknya petaniternak bisa hadir dalam pertemuan kelompok merupakan salah satu kunci akses terhadap informasi berkait dengan usaha ternak sapi perah. Kegiatan kelompok umumnya telah dilaksanakan paling tidak sekali dalam sebulan; informasi yang berasal dari koperasi biasa disampaikan di dalam pertemuan bulanan kelompok sebelum arisan dilak sanakan, hal-hal berkait dengan kegiatan koperasi susu diinformasikan oleh ketua kelompok peternak atau bahkan terkadang oleh pengurus koperasi.

Keberadaan pos penampungan susu segar yang dikelola sedemikian rupa sebagai channeling informasi bagi peternak saat setor susu merupakan hal yang penting di dalam upaya peningkatan human capital. Pada suatu keadaan, informasi menyangkut hasil pe meriksaan kualitas susu segar diumumkan melalui papan informasi di pos-pos penampungan susu segar agar diketahui setiap saat oleh peternak. Selain informasi yang disebarkan secara terbuka, masingmasing peternak secara berkala juga memperoleh informasi yang sifatnya personal berupa informasi tentang jumlah susu segar yang telah disetorkan, kualitas susunya, harga susunya, jenis dan jumlah hutang yang harus dibayar oleh peternak, serta jumlah uang yang didapatnya dari penjualan susu segar.

Munculnya pabrikan pengolah susu segar alternatif tempat peternak dapat menjual susu segar, menjadikan adanya semacam persaingan diam-diam di antara sementara kalangan peternak sapi perah di Ngantang, Semen, maupun Pagu. Kesetiaan peternak sapi perah untuk tetap setor susu kepada koperasi susu via pos penampungan susu menjadi salah satu bahan pertimbangan bagi pihak yang terkait dengan bisnis persusuan dalam hal transparansi informasi tentang kualitas yang kelak berujung kepada harga susu segar yang diterima oleh peternak. Informasi obyektif menyangkut kualitas dan harga susu segar seyogyanya disampaikan secara makin teratur dan transparan, utamanya melalui media pos penampungan susu atau forum pertemuan kelompok peternak sapi perah. Dengan cara demikian, maka pemeliharaan Human Capital dari aspek mutual-trust antara peternak dengan koperasi susu dan pabrikan dapat diupayakan tetap terjaga dan sustainable. 
Tabel 1. Elemen livelihoods-assets rumah tangga peternak sapi perah rakyat pada kajian dua dekade keberadaan Nestle di jawa timur : dampak sosial ekonomi dari penerapan milk district model

\begin{tabular}{|c|c|c|c|}
\hline No. & $\begin{array}{l}\text { Livelihoods } \\
\text { Assets }\end{array}$ & Elemen & Indikator Empirik \\
\hline 1. & $\begin{array}{l}\text { Human Capital } \\
\text { (SDM) }\end{array}$ & $\begin{array}{l}\text { a. Knowledge (pengetahuan) } \\
\text { b. Skills (ketrampilan) } \\
\text { c. Creativity (kreativitas) } \\
\text { d. Adaptive strategy (strategi adaptif) }\end{array}$ & $\begin{array}{l}\text { Pendidikan formal } \\
\text { Pendidikan non-formal } \\
\text { Pola-sistem produksi yang diterapkan } \\
\text { Antisipasi resiko usaha-ternak }\end{array}$ \\
\hline 2. & $\begin{array}{l}\text { Social Capital } \\
\text { (SD Sosial) }\end{array}$ & $\begin{array}{l}\text { a. Government structures (struktur } \\
\text { pemerintah) } \\
\text { b. Decision-making power (kekuatan } \\
\text { pengambilan keputusan) } \\
\text { c. Community and other institution } \\
\text { (masyarakat \& lembaga lain) } \\
\text { d. Participatory processes (proses } \\
\text { partisipatif) } \\
\text { e. Culture (budaya) }\end{array}$ & $\begin{array}{l}\text { Peran di dalam kelembagaan formal } \\
\text { birokrasi } \\
\text { Tingkat partisipasi di dalam } \\
\text { pengambilan keputusan kelompok } \\
\text { masyarakat } \\
\text { Peran di dalam kelembagaan sosial- } \\
\text { lokal } \\
\text { Peran-keaktifan di dalam rembug } \\
\text { kelompok-lainnya } \\
\text { Peran-keaktifan di dalam kegiatan } \\
\text { sosial-kemasyarakatan }\end{array}$ \\
\hline 3. & $\begin{array}{l}\text { Natural Capital } \\
\text { (SDA) }\end{array}$ & $\begin{array}{l}\text { b. Water (air) } \\
\text { c. Forestry-vegetation (hutan- } \\
\text { vegetasi) }\end{array}$ & $\begin{array}{l}\text { Pemilikan-penguasaan lahan dan } \\
\text { beragam akses kepada budidaya } \\
\text { tanaman pangan serta yang } \\
\text { dimanfaatkan sebagai sumber hijauan } \\
\text { pakan ternak. } \\
\text { Akses kepada air bersih } \\
\text { Akses kepada sumber hijauan pakan } \\
\text { ternak }\end{array}$ \\
\hline 4. & $\begin{array}{l}\text { Physical } \\
\text { Capital (SD } \\
\text { Fisik) }\end{array}$ & $\begin{array}{l}\text { a. Buildings, shelter, and housing } \\
\text { (bangunan, permukiman, kandang) } \\
\text { b. Roads (jalan) }\end{array}$ & $\begin{array}{l}\text { Kondisi bangunan rumah tinggal, } \\
\text { kandang ternak, pos penampungan } \\
\text { susu, kantor koperasi } \\
\text { Kondisi infrastruktur transportasi } \\
\text { lokal desa-kecamatan ke pos } \\
\text { penampungan susu dan lainnya. } \\
\text { Pemilikan-penguasaan mesin } \\
\text { produksi, kendaraan dan peralatan } \\
\text { yang dipakai di dalam usaha-ternak } \\
\text { Penguasaan tanaman budidaya } \\
\text { pangan dan pakan ternak }\end{array}$ \\
\hline 5. & $\begin{array}{l}\text { Financial } \\
\text { Capital (SD } \\
\text { Finansial) }\end{array}$ & $\begin{array}{l}\text { a. Cash (dana segar) } \\
\text { b. Savings ( simpanan) } \\
\text { c. Loans-Fundings (kredit, pinjaman } \\
\text { usaha) }\end{array}$ & $\begin{array}{l}\text { Pendapatan usaha-tani ternak } \\
\text { Bentuk-bentuk tabungan rumah } \\
\text { tangga } \\
\text { Sumber pembiayaan-pinjaman }\end{array}$ \\
\hline
\end{tabular}

Keterangan: Indikator empirik dikembangkan berdasarkan konsepsi Sustainable Livelihoods Framework (DFID, 2001) 
Tabel 2. Ikhtisar elemen skor livelihoods assets pada rumah tangga peternak sapi perah rakyat di tiga wilayah kerja koperasi susu di Jawa Timur

\begin{tabular}{lccccc}
\hline \multirow{2}{*}{ Wilayah } & \multicolumn{5}{c}{ Distribusi Elemen Livelihoods Assets Pentagon } \\
& $\begin{array}{c}\text { Human } \\
\text { Capital }\end{array}$ & $\begin{array}{c}\text { Social } \\
\text { Capital }\end{array}$ & $\begin{array}{c}\text { Natural } \\
\text { Capital }\end{array}$ & $\begin{array}{c}\text { Physical } \\
\text { Capital }\end{array}$ & $\begin{array}{c}\text { Financial } \\
\text { Capital }\end{array}$ \\
\hline Ngantang $(\mathrm{n}=50)$ & 2,3 & 3,0 & 2,4 & 2,1 & 2,3 \\
Semen $(\mathrm{n}=25)$ & 2,1 & 3,0 & 2,4 & 1,8 & 2,7 \\
Pagu $(\mathrm{n}=21)$ & 2,9 & 3,1 & 3,0 & 2,5 & 3,2 \\
Rata-rata $(\mathrm{n}=96)$ & 2,4 & 3,0 & 2,5 & 2,1 & 2,6 \\
\hline
\end{tabular}

Sumber: Data Primer, 2007

Tabel 3. Indikator karakteristik rumah tangga peternak sapi perah rakyat di tiga wilayah kerja koperasi susu di Jawa Timur

\begin{tabular}{|c|c|c|c|c|c|}
\hline \multirow[b]{2}{*}{ No. } & \multirow[b]{2}{*}{ Indikator } & \multicolumn{3}{|c|}{ Wilayah Kajian } & \multirow[b]{2}{*}{$\begin{array}{c}\text { Rata-Rata } \\
(\mathrm{n}=96)\end{array}$} \\
\hline & & $\begin{array}{c}\text { Ngantang } \\
\text { Malang } \\
(\mathrm{n}=50)\end{array}$ & $\begin{array}{c}\text { Semen } \\
\text { Blitar } \\
(\mathrm{n}=25)\end{array}$ & $\begin{array}{l}\text { Pagu } \\
\text { Kediri } \\
(\mathrm{n}=21)\end{array}$ & \\
\hline \multirow[t]{15}{*}{1.} & $\begin{array}{l}\text { Capaian Pendidikan Formal } \\
\text { a. Tamat SD }\end{array}$ & & & & \\
\hline & Jumlah (orang) & 44 & 19 & 15 & 78 \\
\hline & Persentase $(\%)$ & 88 & 76 & 71 & 81 \\
\hline & b. Tamat SMP & & & & \\
\hline & Jumlah (orang) & 3 & 2 & 2 & 7 \\
\hline & Persentase $(\%)$ & 6 & 8 & 9 & 7 \\
\hline & c. Tamat SMA & & & & \\
\hline & Jumlah (orang) & 2 & 1 & 1 & 4 \\
\hline & Persentase $(\%)$ & 4 & 4 & 4 & 4 \\
\hline & d. Tamat Perguruan Tinggi & & & & \\
\hline & Jumlah (orang) & 0 & 1 & 2 & 3 \\
\hline & Persentase (\%) & 0 & 4 & 9 & 3 \\
\hline & e. Tidak Sekolah & & & & \\
\hline & Jumlah (orang) & 1 & 2 & 1 & 4 \\
\hline & Persentase $(\%)$ & 2 & 8 & 4 & 4 \\
\hline \multirow[t]{9}{*}{2.} & $\begin{array}{l}\text { Pekerjaan Utama Peternak: } \\
\text { a. Petani }\end{array}$ & & & & \\
\hline & Jumlah (orang) & 29 & 7 & 1 & 36 \\
\hline & Persentase (\%) & 58 & 24 & 5 & 38 \\
\hline & b. Peternak Sapi Perah & & & & \\
\hline & Jumlah (orang) & 21 & 18 & 18 & 57 \\
\hline & Persentase (\%) & 42 & 72 & 86 & 59 \\
\hline & c. Lainnya & & & & \\
\hline & Jumlah (orang) & 0 & 1 & 2 & 3 \\
\hline & Persentase (\%) & 0 & 4 & 10 & 3 \\
\hline
\end{tabular}

Sumber: Data Primer, 2007 
Tabel 4. Indikator empirik kreativitas dan strategi adaptif pada human capital rumah tangga peternak sapi perah rakyat

\begin{tabular}{llcccccccc}
\hline Indikator Empirik & \multirow{2}{*}{ Kategori } & \multicolumn{2}{c}{ Ngantang } & \multicolumn{2}{c}{ Semen } & \multicolumn{2}{c}{ Pagu } & \multicolumn{2}{c}{ Rata-Rata } \\
\cline { 3 - 10 } & & $(\mathrm{n})$ & $(\%)$ & $(\mathrm{n})$ & $(\%)$ & $(\mathrm{n})$ & $(\%)$ & $(\mathrm{n})$ & $(\%)$ \\
\hline 1. Creativity & Tinggi (4-5) & 5 & 10 & 2 & 8 & 3 & 14 & 10 & 11 \\
& Sedang $>2<3$ & 37 & 74 & 21 & 84 & 17 & 81 & 76 & 80 \\
& Rendah (0-2) & 8 & 16 & 2 & 8 & 1 & 5 & 9 & 10 \\
2. Adaptive Strategies & & & & & & & & & \\
& Tinggi (4-5) & 9 & 18 & 0 & 0 & 3 & 14 & 10 & 11 \\
& Sedang $>2<3$ & 32 & 64 & 20 & 80 & 18 & 86 & 74 & 77 \\
& Rendah (0-2) & 9 & 18 & 5 & 20 & 0 & 0 & 12 & 13 \\
\hline
\end{tabular}

Sumber: Data Primer, 2007

Tabel 5. Indikator empirik social capital rumah tangga peternak sapi perah rakyat

\begin{tabular}{|c|c|c|c|c|c|c|c|c|c|}
\hline \multirow{2}{*}{ Indikator Empirik } & \multirow{2}{*}{ Kategori } & \multicolumn{2}{|c|}{ Ngantang } & \multicolumn{2}{|c|}{ Semen } & \multicolumn{2}{|c|}{ Pagu } & \multicolumn{2}{|c|}{ Rata-Rata } \\
\hline & & $\mathrm{N}$ & $\%$ & $\mathrm{n}$ & $\%$ & $\mathrm{~N}$ & $\%$ & $\mathrm{n}$ & $\%$ \\
\hline Peran di dalam kelembagaan & Tinggi (4-5) & 9 & 18 & 2 & 8 & 1 & 5 & 10 & 10 \\
\hline \multirow{2}{*}{ formal } & Sedang $>2<$ & 30 & 60 & 16 & 64 & 11 & 52 & 56 & 59 \\
\hline & Rendah (0-2) & 11 & 22 & 7 & 28 & 9 & 43 & 30 & 31 \\
\hline \multirow[t]{3}{*}{ Partisipasi dalam kelompok } & Tinggi (4-5) & 3 & 6 & 4 & 16 & 7 & 33 & 7 & 7 \\
\hline & Sedang $>2<3$ & 8 & 16 & 4 & 16 & 4 & 19 & 16 & 17 \\
\hline & Rendah $(0-2)$ & 39 & 78 & 17 & 68 & 10 & 48 & 73 & 76 \\
\hline Peran di dalam kelembagaan & Tinggi (4-5) & 1 & 2 & 1 & 4 & 0 & 0 & 2 & 2 \\
\hline \multirow{2}{*}{ sosial-lokal } & Sedang $>2<3$ & 15 & 30 & 9 & 36 & 8 & 38 & 33 & 35 \\
\hline & Rendah (0-2) & 34 & 68 & 15 & 60 & 13 & 62 & 61 & 63 \\
\hline \multirow{3}{*}{$\begin{array}{l}\text { Peran-keaktifan di dalam } \\
\text { rembug kelompok-lainnya }\end{array}$} & Tinggi (4-5) & 1 & 2 & 1 & 4 & 1 & 5 & 3 & 4 \\
\hline & Sedang $>2<3$ & 14 & 28 & 9 & 36 & 8 & 38 & 33 & 34 \\
\hline & Rendah (0-2) & 35 & 70 & 15 & 60 & 12 & 57 & 60 & 62 \\
\hline an di dalam & Tinggi (4-5) & 9 & 18 & 1 & 4 & 2 & 10 & 10 & 11 \\
\hline kegiatan sosial & Sedang $>2<3$ & 33 & 66 & 23 & 92 & 19 & 90 & 80 & 83 \\
\hline kemasyarakatan & Rendah (0-2) & 8 & 16 & 1 & 4 & 0 & 0 & 6 & 7 \\
\hline
\end{tabular}

Sumber : Data Primer, 2007

Tabel 6. Indikator empirik natural capital rumah tangga peternak sapi perah rakyat

\begin{tabular}{lccccccccc}
\hline & & \multicolumn{2}{c}{ Ngantang } & \multicolumn{2}{c}{ Semen } & \multicolumn{2}{c}{ Pagu } & \multicolumn{2}{c}{ Rata-Rata } \\
Indikator Empirik & Kategori & $\mathrm{n}$ & $\%$ & $\mathrm{~N}$ & $\%$ & $\mathrm{~N}$ & $\%$ & $\mathrm{n}$ & $\%$ \\
\hline Water Resources & Tinggi (4-5) & 6 & 12 & 0 & 0 & 2 & 10 & 7 & 7 \\
& Sedang $>2<3$ & 37 & 74 & 25 & 100 & 19 & 90 & 85 & 88 \\
& Rendah (0-2) & 7 & 14 & 0 & 0 & 0 & 0 & 4 & 5 \\
Forest-Vegetation & Tinggi (4-5) & 7 & 14 & 0 & 0 & 1 & 5 & 6 & 6 \\
& Sedang $>2<3$ & 27 & 54 & 13 & 52 & 4 & 19 & 40 & 42 \\
& Rendah (0-2) & 16 & 32 & 12 & 48 & 16 & 76 & 50 & 52 \\
\hline
\end{tabular}

Sumber: Data Primer, 2007 
Aksesibilitas peternak sapi perah kepada Social Capital. Rata-rata indikator kumulatif Social Capital menunjukkan sedang (nilai skor 3,0). Dalam konteks sustainable livelihoods framework, Social Capital diartikan sebagai 'the social resources upon which people draw in pursuit of their livelihood objectives', yang di dalamnya terdiri dari elemen aksesibilitas rumah tangga peternak sapi perah kepada jaringan dan keterhubungan (connectedness) antara rumah tangga peternak satu dengan lainnya, serta antara rumah tangga peternak sapi perah dengan suprastruktur dimana mereka berusaha bekerjasama mencapai tujuan tertentu. Selain itu, derajad aksesibilitas rumah tangga peternak sapi perah kepada kelompok formal maupun nonformal semisal kelompok peternak sapi perah, kelompok arisan dan kelompokkelompok sosial kemasyarakatan ataupun keagamaan dimana terjalin relationship of trust, reciprocity dan exchanges menjadikan suatu rumah tangga memiliki Social Capital yang dapat digunakan sebagai salah satu alat untuk mencapai tujuan usaha secara individual maupun kolektif.

Derajat kekuatan yang terakumu lasikan di dalam Social Capital yang terbangun secara luas, egaliter dan fokus, akan dapat muncul menjadi semacam ke kuatan penekan bagi kekuatan institusi lain yang menempatkan diri secara saling berhadapan (Sulastri and Maharjan, 2002). Oleh karena itu, salah satu teknik untuk menjinakkan dan mengambil energi positif Social Capital yang massive, adalah menumbuhkan dan menguatkan jaringan kerjasama kemitraan sejajar secara langsung (untuk mencegah free-rider) antar pemangku kepentingan (shareholder - stakeholder). Selain itu, tidak kalah penting untuk diperhatikan pula dalam hal Social Capital, adalah adanya hubungan darah kekerabatan (kinship) antar satu keluarga peternak dengan keluarga peternak lainnya, yang tidak jarang memungkinkan timbulnya mekanisme jaringpengaman (safety-net) pada suatu komunitas peternak sapi perah.
Indikator empirik Social Capital menunjukkan bahwa mayoritas rumah tangga peternak sapi perah yang ada di Ngantang, Semen maupun Pagu memiliki nilai rendah pada tingkat partisipasi di dalam kelompok, peran di dalam kelembagaan sosial-lokal, dan keaktifan di dalam rembug kelompok lainnya. Sementara itu, peran di dalam kelembagaan formal dan dalam kegiatan sosial-ke masyarakatan adalah sedang.

Kenyataan dilapangan menunjukkan bahwa overlap fungsi antara kelompok peternak sapi perah dengan fungsi-fungsi lain seperti kelompok sosial-kemasyarakatan lainnya kadang terjadi (Andri. and Shiratake 2003). Sehingga keduanya justru sama-sama tidak dapat berjalan secara baik. Jika kelompok peternak masih dianggap sebagai organisasi yang dapat dipakai sebagai sarana untuk mencapai tujuan usaha persusuan dan salah satunya berujung kepada upaya peningkatan kesejahteraan anggota kelompok peternak sapi perah, maka peran kelompok peternak sapi perah di dalam interaksi dengan pihak lain di dalam bisnis persusuan melalui koperasi susu semestinya mendapatkan perhatian untuk makin di berdayakan. Apalagi jika dikaitkan dengan fungsi-fungsi channeling sehubungan dengan keberadaan koperasi persusuan dalam hal distribusi sapronak maupun proses koleksi susu segar dari para peternak sapi perah.

Rendahnya tingkat partisipasi di dalam kelompok peternak sapi perah mungkin saja terjadi karena keuntungan dan manfaat kelompok peternak belum terapresiasi dengan baik oleh anggotanya. Logikanya mudah, anggota kelompok peternak secara otomatis akan berperan makin aktif jika kelompok dan suprastrukturnya mampu memberikan keuntungan dan manfaat yang secara riil diterima oleh anggota.

\footnotetext{
Aksesibilitas peternak sapi perah kepada Natural Capital. Aksesibilitas rumahtangga peternak sapi perah kepada Natural Capital dengan indikator kondisi akses kepada air bersih dan biomassa vegetasi sumber hijauan pakan umumnya adalah sedang dan rendah (skor 2,5). Untuk
} 
kondisi Pagu, karena berada pada altitude yang relatif lebih rendah dari pada Ngantang dan Semen, maka akses kepada air bersih relatif lebih mudah dibandingkan dengan Ngantang maupun Semen; bahkan untuk kondisi seperti di Ngantang (SalamPagersari), ada beberapa rumah tangga peternak sapi perah memiliki aksesibilitas rendah kepada air bersih karena kondisi topografis setempat; sementara jaringan distribusi air bersih nampaknya masih banyak memerlukan perbaikan agar aliran air bersih untuk keperluan budidaya sapi perah maupun keperluan rumah tangga lainnya bisa lebih teratur dan lancar setiap saat. Aksesibilitas air bersih sampai dengan tingkat rumah tangga peternak secara langsung berpengaruh kepada performans produksi susu segar, utamanya pada indikator status hygiene susu yang disetorkan ke koperasi susu via pos penampungan susu.

Upaya memang telah dikerjakan dengan perbaikan akses kepada air bersih di tingkat pos penampungan susu dengan tujuan agar peternak dapat mencuci milk-can (pakai larutan typol) di pos penampungan susu segera setelah setor susu.Usaha peningkatan aksesibilitas kepada air bersih sampai ke tingkat rumah tangga peternak dan kandang sapi melalui perbaikan sarana distribusi air bersih, tentu masih perlu ditingkatkan dengan melibatkan banyak pihak dan terintegrasi dengan kegiatan konservasi sumber air bersih secara makin sungguh-sungguh (Tabel 6).

Tidak mudah mendapati rumah tangga peternak sapi perah rakyat yang memilikimenguasai lahan budidaya tanaman luas dan apalagi yang memiliki lahan khusus untuk penanaman tanaman sumber hijauan makanan ternak. Secara umum dapat dinyatakan bahwa jenis lahan yang dimiliki atau dikuasai peternak sapi perah selain pekarangan yang ditempati rumah bervariasi mulai dari kebun, tegalan, sampai dengan sawah; lahan tegalan nampaknya umum dimiliki-dikuasai. Luasnya pun cukup beragam, mulai dari yang tidak memiliki lahan sama sekali sampai dengan yang memiliki atau menguasai sekitar 0,5 hektar (Tabel 7). Di tegalan terdapat macam-macam vegetasi baik yang sengaja dibudidayakan untuk keperluan rumah tangga sehari-hari, tanaman tahunan dan rerumputan (rumput Kolonjono) sebagai sumber hijauan makanan ternak. Untuk situasi Ngantang dan Semen, banyak peternak sapi perah memiliki akses kepada lahan perkebunan milik PT. Perhutani dengan kewajiban-kewajiban ter tentu yang harus dipenuhi. Peternak sapi perah di Pagu tidak memiliki akses semacam itu; rumput sumber hijauan makanan ternak memang sengaja ditanam di tegalan, pinggir areal persawahan, bahkan di pekarangan dekat rumah. Yang jelas, dengan kondisi seperti itu, kontinuitas pasokan hijauan tidak selalu dapat diandalkan, terutama pada saat menjelang pertengahan musim kemarau. Pemakaian tebon jagung sebagai hijauan pakan sapi perah beberapa waktu yang lalu merupakan salah satu alternatif pada saat paceklik hijauan; namun belakangan peternak sapi perah mengkhawatirkan adanya residu bahan kimia dari pemakaian pestisida terhadap tanaman jagung (atau aplikasi kepada tanaman lain) dapat menyebabkan sapi perah yang diberi pakan tebon jagung menjadi sempoyongan-mabuk.

Usaha penanaman leguminosa pakan ternak telah pernah dilaksanakan, misalnya di Pagersari, Ngantang; namun praktek pemberiannya kepada sapi perah masih terdapat kendala pada sisi peternak yang tidak mau ribet. Alternatif metode pemberian hijauan leguminosa yang dapat diterima oleh peternak masih perlu dicarikan, misalnya dengan cara pabrikasi legume leaf-meal (tepung daun leguminosa); sehingga lebih mudah mengikutkannya ke dalam bahan penyusun pakan konsentrat. Pabrikasi tepung daun leguminosa hanya merupakan salah satu upaya untuk membantu memastikan ter jaminnya pasok bahan pakan ternak penyusun konsentrat sapi perah yang kian rawan, sehingga harus ada upaya yang secara spesifik melaksanakan feedstuffssourcing and development, dan sedapatnya 
dikaitkan dengan upaya konservasi lingkungan bio-fisik.

Aksesibilitas peternak sapi perah kepada Physical Capital. Rata-rata derajad aksesibilitas rumah tangga terhadap Physical Capital termasuk dalam kateori sedang (skor 2,1). Indikator empirik berkenaan dengan sarana rumah pemukiman peternak sapi perah dan infrastruktur penunjangnya menunjukkan bahwa wilayah Pagu memiliki aksesibilitas yang relatif lebih tinggi daripada Semen, dan Semen adalah lebih baik daripada Ngantang. Prasarana transportasi berupa jalan yang ada di Pagu relatif lebih baik; demikian pula sarana transportasi berupa kendaraan yang dipakai oleh peternak sapi perah, misalnya ketika pergi setor susu ke pos penampungan susu atau ngarit (Tabel 8). Beberapa usaha untuk memperbaiki kualitas infrastruktur jaringan jalan terus diupayakan untuk memperlancar distribusi pakan konsentrat sapi perah kepada para peternak di sekitar pos penampungan susu Salam-Pagersari-Ngantang. Prasarana fisik bangunan pos penampungan susu telah cukup baik, namun masih perlu terus diperbaiki agar mampu memberikan pelayanan standard sesuai dengan prosedur operasional penanganan susu segar dari tangan peternak sapi perah secara maksimal bersih dan cepat.

Sementara itu, gambaran umum kondisi kandang tempat pemeliharaan sapi perah menunjukkan masih rendahnya perhatian terhadap kebersihan lingkungan di sekitar kandang sapi. Kekhawatiran terhadap pengaruh tidak baik terhadap keadaan kesehatan ternak maupun keluarga peternak cukup beralasan. Sehubungan dengan itu, nampaknya upaya untuk memperbaiki lingkungan sekitar kandang sapi dan pemukiman peternak masih sangat diperlukan melalui teknologi pemanfaatan kotoran dan limbah usaha peternakan rakyat yang dapat dioperasikan secara kolektif antara sesama peternak sapi perah.

Kondisi kandang serta beragam alat yang dipakai di dalam aktivitas budidaya sapi perah tidak menunjukkan banyak keragaman dalam jenis maupun kualitasnya mulai dari bahan yang dipakai untuk bangunan kandang, meskipun telah ada sementara peternak yang mengupayakan pengaturan kandang sede mikian rupa, sehingga kekhawatiran dampak negatif terhadap kesehatan sapi maupun keluarganya dapat dikurangi.

Tabel 7. Gambaran pemilikan-penguasaan lahan pada rumah tangga peternak sapi perah

\begin{tabular}{cllcc}
\hline No. & Lokasi & \multicolumn{1}{c}{ Jenis Lahan } & Rata-Rata \pm SD (ha) & $(\%)$ \\
\hline 1. & Ngantang, $\mathrm{n}=50$ & a. Sawah & $0,27 \pm 0,19$ & 26 \\
& & b. Tegalan & $0,43 \pm 0,36$ & 43 \\
& & c. Pekarangan & $0,05 \pm 0,04$ & 5 \\
2. & d. Kebun & $0,27 \pm 0,14$ & 26 \\
& & a. Sawah & $0,14 \pm 0,06$ & 16 \\
& & b. Tegalan & $0,35 \pm 0,16$ & 41 \\
& & c. Pekarangan & $0,10 \pm 0,08$ & 12 \\
3. & Pagu, $\mathrm{n}=21$ & d. Kebun & $0,27 \pm 0,14$ & 31 \\
& & a. Sawah & $0,39 \pm 0,16$ & 72 \\
& & b. Tegalan & $0,08 \pm 0,04$ & 15 \\
4. & Rata-rata, $\mathrm{n}=96$ & c. Pekarangan & $0,07 \pm 0,06$ & 13 \\
& & d. Kebun & $0,00 \pm 0,00$ & 0 \\
& & a. Sawah & $0,27 \pm 0,11$ & 29 \\
& & b. Tegalan & $0,32 \pm 0,20$ & 36 \\
& & c. Pekarangan & $0,07 \pm 0,03$ & 8 \\
\hline
\end{tabular}

Sumber: Data Primer, 2007 
Tabel 8. Indikator empirik Physical Capital rumah tangga peternak sapi perah rakyat

\begin{tabular}{llccccccccc}
\hline \multirow{2}{*}{ Indikator Empirik } & Kategori & \multicolumn{3}{c}{ Ngantang } & \multicolumn{2}{c}{ Semen } & \multicolumn{2}{c}{ Pagu } & \multicolumn{2}{c}{ Rata-Rata } \\
\cline { 3 - 10 } & & $\mathrm{N}$ & $\%$ & $\mathrm{n}$ & $\%$ & $\mathrm{n}$ & $\%$ & $\mathrm{n}$ & $\%$ \\
\hline Buildings-Housing & Tinggi (4-5) & 5 & 10 & 3 & 12 & 3 & 14 & 12 & 12 \\
& Sedang $>2<3$ & 28 & 56 & 18 & 72 & 15 & 71 & 64 & 66 \\
& Rendah (0-2) & 17 & 34 & 4 & 16 & 3 & 14 & 21 & 21 \\
Roads & Tinggi (4-5) & 1 & 2 & 0 & 0 & 10 & 48 & 11 & 12 \\
& Sedang >2<3 & 31 & 62 & 15 & 58 & 4 & 19 & 49 & 51 \\
Machinery & Rendah (0-2) & 18 & 36 & 11 & 42 & 7 & 33 & 36 & 38 \\
& Tinggi (4-5) & 6 & 12 & 3 & 12 & 5 & 24 & 14 & 15 \\
Crops-Livestock & Sedang >2<3 & 25 & 50 & 7 & 28 & 10 & 48 & 40 & 42 \\
& Rendah (0-2) & 19 & 38 & 15 & 60 & 6 & 29 & 42 & 44 \\
& Tinggi (4-5) & 3 & 6 & 4 & 16 & 5 & 24 & 15 & 15 \\
& Sedang >2<3 & 23 & 46 & 12 & 48 & 10 & 48 & 45 & 47 \\
& Rendah (0-2) & 24 & 48 & 9 & 36 & 6 & 29 & 36 & 38 \\
\hline
\end{tabular}

Sumber: Data Primer, 2007

Tabel 9. Indikator empirik Financial Capital rumah tangga peternak sapi perah rakyat

\begin{tabular}{llllllllll}
\hline \multirow{2}{*}{ Indikator Empirik } & \multirow{2}{*}{ Kategori } & \multicolumn{1}{c}{ Ngantang } & \multicolumn{2}{c}{ Semen } & \multicolumn{2}{c}{ Pagu } & \multicolumn{2}{c}{ Rata-Rata } \\
\cline { 3 - 10 } & & $\mathrm{N}$ & $\%$ & $\mathrm{n}$ & $\%$ & $\mathrm{n}$ & $\%$ & $\mathrm{~N}$ & $\%$ \\
\hline \multirow{3}{*}{ Cash } & Tinggi (4-5) & 7 & 14 & 2 & 8 & 4 & 19 & 13 & 14 \\
& Sedang $>2<3$ & 33 & 66 & 19 & 76 & 14 & 67 & 67 & 70 \\
& Rendah (0-2) & 10 & 20 & 4 & 16 & 3 & 14 & 16 & 17 \\
Savings & & & & & & & & & \\
& Tinggi (4-5) & 21 & 42 & 4 & 16 & 4 & 19 & 25 & 26 \\
& Sedang $>2<3$ & 17 & 34 & 14 & 56 & 16 & 76 & 50 & 52 \\
Loans & Rendah (0-2) & 12 & 24 & 7 & 28 & 1 & 5 & 21 & 22 \\
& & & & & & & & & \\
& Tinggi (4-5) & 3 & 6 & 1 & 4 & 1 & 5 & 5 & 5 \\
& Sedang $>2<3$ & 3 & 6 & 2 & 8 & 16 & 76 & 29 & 30 \\
& Rendah $(0-2)$ & 44 & 88 & 22 & 88 & 4 & 19 & 62 & 65 \\
\hline
\end{tabular}

Sumber: Data Primer (Desember, 2007)

Upaya pengerasan lantai kandang dengan semen (ada peternak yang mampu memberi alas karet pada lantai kandang), pembuatan palungan tempat pakan hijauan dan konsentrat, saluran pembuangan limbah dan kotoran dari lokasi kandang yang telah terbuat dari semen (tetapi masih bermuara kepada parit umum di kampung).

Sarana yang terdapat pada pos penampungan susu segar relatif memadai dengan adanya milk-chiller yang memerlukan tenaga listrik, serta berbagai peralatan pengujian kualitas susu segar sederhana sehingga memungkinkan dilaksanakan pengujian secara terintegrasi dengan pengukuran jumlah susu yang disetorkan oleh peternak. Emplasmen untuk milk-transfer tank juga telah tersedia pada kondisi cukup baik, dan telah memungkinkan kegiatan transfer susu segar dari chiller ke dalam milk-transfer tank dapat dikerjakan dengan relatif cepat (+30 menit) (Tabel 8). 
Tabel 10. Gambaran skala pemeliharaan sapi perah pada rumah tangga peternak

\begin{tabular}{|c|c|c|c|c|c|c|c|c|}
\hline \multirow[t]{2}{*}{ Deskripsi Sapi } & \multicolumn{2}{|c|}{$\begin{array}{c}\text { Ngantang } \\
(\mathrm{n}=50)\end{array}$} & \multicolumn{2}{|c|}{$\begin{array}{l}\text { Semen } \\
(\mathrm{n}=25)\end{array}$} & \multicolumn{2}{|c|}{$\begin{array}{c}\text { Pagu } \\
(\mathrm{n}=21)\end{array}$} & \multicolumn{2}{|c|}{$\begin{array}{c}\text { Rata-Rata } \\
(\mathrm{n}=96)\end{array}$} \\
\hline & (ekor) ${ }^{1}$ & $(\%)^{2}$ & (ekor) ${ }^{1}$ & $(\%)^{2}$ & $(\mathrm{ekor})^{1}$ & $(\%)^{2}$ & $(\text { ekor })^{1}$ & $(\%)^{2}$ \\
\hline Induk Laktasi & 2 & 56 & 3 & 29 & 4 & 32 & 3 & 26 \\
\hline Induk Kering & 2 & 11 & 1 & 14 & 1 & 13 & 1 & 14 \\
\hline Dara & 2 & 14 & 1 & 13 & 2 & 15 & 2 & 15 \\
\hline Pedet Jantan & 1 & 5 & 2 & 18 & 2 & 14 & 1 & 13 \\
\hline Pedet Betina & 1 & 12 & 1 & 15 & 2 & 16 & 1 & 13 \\
\hline Jantan Muda & 1 & 0 & 1 & 11 & 0 & 0 & 1 & 9 \\
\hline Jantan Dewasa & 3 & 1 & 0 & 0 & 1 & 9 & 1 & 9 \\
\hline
\end{tabular}

Keterangan: ${ }^{1}$ Angka rata-rata, ${ }^{2}$ Dari jumlah peternak masing-masing lokasi Sumber: Data Primer, 2007

\section{Aksesibilitas peternak sapi perah kepada Financial Capital. Financial Capital} rumah tangga peternak sapi perah secara rata-rata menunjukkan kategori sedang (skor 2,6). Kondisi di Pagu relatif lebih tinggi dibandingkan dengan dua wilayah lainnya; hal itu dapat disebabkan bahwa secara geografis, wilayah Pagu berada pada jarak relatif dekat dengan spot aktivitas ekonomi masyarakat, dan aktivitas ekonomi masyarakat umumnya tersebut telah terdukung oleh adanya beragam fasilitas jasa pendanaan seperti Bank Perkreditan Rakyat (BPR) yang dioperasikan oleh bank pemerintah maupun suasta, bermacam jasa Unit Simpan Pinjam Koperasi. Di samping itu, tingginya derajat Financial Capital di Pagu dapat pula disebabkan oleh tingginya nilai liabilitas aset yang ada pada masyarakat Pagu.

Uang kontan yang ada pada rumah tangga peternak sapi perah merupakan salah satu indikator empirik Financial Capital. Kenyataan menunjukkan bahwa mayoritas peternak mengaku selalu memiliki (baca memegang) uang kontan (fresh-money) untuk memenuhi kebutuhan sehari-hari (beli sembako) untuk menjaga household food security. Memang secara reguler-periodik, peternak menerima uang dari hasil pembayaran susu yang disetorkan ke koperasi susu. Di samping itu, mereka memiliki akses langsung terhadap liableassets berupa sapi perah yang ada di kandang. Sapi perah yang ada di kandang, secara cepat dan mudah dapat ditukar dengan fresh-money setiap saat, apalagi sapi perah yang berstatus milik sendiri. Gambaran skala pemeliharaan sapi perah menunjukkan bahwa liable-assets yang riil ada di kandang dan mudah diuangkan adalah induk laktasi, sapi dara, dan pedet betina.

Dengan membaiknya harga susu segar yang diterima oleh peternak sapi perah, nilai jual sapi perah produktif, sapi dara, dan pedet betina mengalami kenaikan yang sangat berarti. Dengan demikian, maka aksesibilitas financial peternak sapi perah berupa sapi produktif memiliki nilai makin tinggi.

Bagi peternak sapi perah yang kondisinya cukup kuat untuk menjalankan strategi tetap memelihara pedet jantan, jantan muda, dan jantan dewasa memiliki aksesibilitas financial lebih kuat lagi; karena hal itu akan mendatangkan economic-gain lebih besar dan lebih cepat. Pada dasarnya hampir seluruh peternak sapi perah rakyat berskala kecil merasa nyaman menabung tidak dalam bentuk uang di bank; mereka lebih memilih menabung dalam wujud natura berupa sapi. Memang sebagian peternak ada yang menabung dalam bentuk perhiasan pada isteri atau dirupakan dalam bentuk lahan pertanian atau kendaraan bermotor. Bagi peternak yang menabung dalam bentuk ternak betina memiliki arti strategis dalam kaitan dengan upaya meningkatkan farm-size ataupun kepentingan replacement. Dari pada pinjam di bank atau koperasi untuk dua keperluan tersebut terdahulu, pilihan 
menabung dalam bentuk sapi perah betina adalah pilihan yang paling masuk akal. Pinjaman (loans) di koperasi, menurut peternak sapi perah, kalau bisa hanya berupa potongan bayaran karena adanya hutang pakan konsentrat dan keperluan sarana produksi lainnya.

\section{KESIMPULAN}

Dari sudut pandang aksesibilitas terhadap sumber daya finansial, usaha budidaya ternak sapi perah terbukti mampu meningkatkan sirkulasi cash-money dari wilayah pusat ke wilayah pedesaan. Tingkat aksesibilitas peternak terhadap sumberdaya finansial dan sosial relatif lebih tinggi di banding dengan tingkat aksesibilitas terhadap sumberdaya manusia, fisik dan SDA. Sedangkan tingkat aksesibilitas peternak ter hadap sumberdaya manusia, fisik dan SDA relatif masih lemah dan perlu untuk lebih ditingkatkan dimasa mendatang melalui perubahan mindset, perbaikan infrastruktur serta penyediaan akses yang lebih baik terhadap sarana air bersih.

\section{DAFTAR PUSTAKA}

Ackerman, W. Smith, A. and Peterson, S. 2005. "Nestlé S.A.: One Small Step, One Giant Leap," Equity Research: Switzerland, Citigroup Smith Barney.

Andri, K.B. and Shiratake, Y. 2003. Existence, Types And Opportunities Of
Contract Farming In East Java. Bulletin Faculty of Agriculture, Saga University, Japan. No 88: 43-55.

Ashley, C. Hussein, K. 2000. Working Paper 129: Developing Methodologies for Livelihood Impact Assessment, Livelihoods Support Programs Working Paper. FAO, Rome.

Cleary, D., Baumann, P., Bruno, M., Flores, X., and Warren, P. 2003. PeopleCentred Approaches: A Brief Literature Review and Comparison of Types. Livelihoods Support Programme (LSP) Working Paper 5, June 2004. FAO. Rome.

Department of International Development (DFID). 2001. Sustainable Livelihoods Guidance Sheets. London. United Kingdom.

Dispet Jatim. 2005. Buku Laporan Tahunan Dinas Peternakan Provinsi Jawa Timur.

Goldberg, R A. 2005. Nestlé's Milk District Model: Economic Development For A Value-Added Food Chain AndImproved Nutrition.Global Research Group.

Sulastri, E and Maharjan, K L. 2002. Role of Dairy Cooperative Services on DairyDevelopment in Indonesia. A Case Study of Daerah Istimewa Yogyakarta Province. Journal of International Development and Cooperation, 9(1), 17-39. 